\title{
Synthesis and Evaluation of the Semiconductor Behavior in Vanadium Indanone Derivatives Thin Films
}

\author{
Mariana Lozano-González1, María Elena Sánchez-Vergara ${ }^{2 *}$, Isabel Alvarado-Beltrán1, \\ Mariel Leyva-Esqueda², Margarita Rivera ${ }^{3}$, Cecilio Álvarez-Toledano ${ }^{{ }^{*}}$ \\ ${ }^{1}$ Institute of Chemistry, National Autonomous University of Mexico, Mexico City, Mexico \\ ${ }^{2}$ Anahuac University, Mexico City, Mexico \\ ${ }^{3}$ Institute of Physics, National Autonomous University of Mexico, Mexico City, Mexico \\ Email: ^elena.sanchez@anahuac.mx, ${ }^{*}$ cecilio@unam.mx
}

How to cite this paper: Lozano-González, M., Sánchez-Vergara, M.E., Alvarado-Beltrán, I., Leyva-Esqueda, M., Rivera, M. and Álvarez-Toledano, C. (2017) Synthesis and Evaluation of the Semiconductor Behavior in Vanadium Indanone Derivatives Thin Films. Advances in Materials Physics and Chemistry, 7, 70-83.

https://doi.org/10.4236/ampc.2017.72007

Received: January 3, 2017

Accepted: February 25, 2017

Published: February 28, 2017

Copyright $\odot 2017$ by authors and Scientific Research Publishing Inc. This work is licensed under the Creative Commons Attribution International License (CC BY 4.0).

http://creativecommons.org/licenses/by/4.0/ (c) (i) Open Access

\begin{abstract}
In this work, we propose a method to synthesize vanadium (IV) 2-benzyli-dene-1-indanone derivatives, used to prepare film structures by thermal evaporation. The complexes possess high melting point allowing the using of vacuum deposition methods. All the samples were grown at room temperature $\left(25^{\circ} \mathrm{C}\right)$ and low deposition rates $(0.4 \AA / \mathrm{s})$. The surface morphology and structure of the deposited films were studied by scanning electron microscopy (SEM) and spectroscopy dispersive energy (EDS). Optical absorption studies of the complex films were performed in the $200-1100 \mathrm{~nm}$ wavelength range. The Tauc band gap (Eg) of the thin films was determined from the $(\alpha h v)^{1 / 2} v s$. $\mathrm{h} v$ plots for indirect transitions. The vanadium (IV) complex films show optical activation energies in the range of organic semiconductors. Multilayer nylon 11/vanadium indanone devices were fabricated using ITO and silver electrodes. The d.c. electrical properties of the device were also investigated. It was found that the temperature-dependent electric current in the structure showed a semiconductor behavior. At lower voltages below $7 \mathrm{~V}$, the current density in the forward direction was found to obey an ohmic I-V relationship; for higher voltages above $7 \mathrm{~V}$, the conduction was dominated by a space-charge-limited (SCLC) mechanism. The electrical activation energies (Ea) of the complexes were in the $2.17-2.31 \mathrm{eV}$ range.
\end{abstract}

\section{Keywords}

Chemical Synthesis, Thin Films, Optical Properties, Electrical Properties

\section{Introduction}

The use of organic semiconductors in the manufacture of electronic gadgets such 
as light-emitting diodes, rechargeable batteries, sensors, and electronic devices, has shown a rapid increase in recent years. The low cost of manufacturing organic semiconductors, easy manipulation of specific properties and their compatibility to relatively cheap substrates when they are deposited as thin films, are the main causes for this upsurge. Organic semiconductors also show excellent properties at relatively low temperatures such as high electroluminescence, good charge mobilities, and mechanical flexibility, among others. The main difference between organic semiconductors compared with single atom inorganic semiconductors is the presence of separate molecules, which maintain most of their characteristics even in the solid-state form [1]. These single molecule characteristics are reflected in the optical and electrical properties like absorption, gap and the transport of charge carriers [2]. Molecules including transition metals more commonly provide better results as organic semiconductors. The presence of transition metals with $d$ orbitals favors intramolecular conduction channels, where electric charges can freely circulate, providing preferential directions or anisotropy in the material. Additionally, coordination compounds with active redox metals that exhibit paramagnetic properties often undergo electronic excitations with visible light, which increases the possibilities to be used as organic semiconductor materials.

Under these circumstances, vanadium compounds can be exploited to produce organic semiconductors, magnetic materials and display devices [3] [4]. Vanadium complexes have been a growing topic of research because of their versatile physicochemical properties [4] [5]. The oxovanadium (IV) ion is one of the most known stable diatomic ions and its paramagnetic physicochemical and electronic properties with Schiff base are of great interest in different research fields [6]. Although the oxovanadium with diketones is a highly studied liquid crystal known as metallomesogensoxovanadium [7] [8] [9], there are no reports about the study of its optical properties as a thin film. Although there are not too many reports on the preparation of these films by thermal vacuum evaporation [10] [11], the important properties of vanadium have been attributed to the stability of its different oxidation states.

Preliminary results of the study of iron (III) complexes of 2-benzylidene-1indanone derivatives thin films showed that the chemical differences between the substituents in the complexes and the structural variations did not have a great impact in the band gap value. Nevertheless, the metal arrangements during the thin film formation provided a glimpse on the optical properties of these compounds [12]. In this context, we continue the study of the behavior of new 2-benzylidene-1-indanone metal complexes derivatives with vanadium. These compounds were previously synthesized and characterized both, chemically and structurally through IR, mass spectroscopy, and NMR. As previously mentioned, thin films of these complexes were prepared by thermal evaporation and they were characterized by SEM, EDS and IR spectroscopy. We also report the acquisition of optical parameters related to the main transitions in the UV-Vis region and the fundamental energy gap calculations for these films. The multilayer glass/ITO/ny- 
lon 11/vanadium indanone/Ag device was fabricated by vacuum thermal evaporation. Finally, the transport characteristics of these devices were also studied by using d.c. electrical measurements.

\section{Experimental Section}

\subsection{General Information}

All reagents were obtained from commercial suppliers and used without further purification. The compounds were characterized by IR spectra, recorded on a Perkin-Elmer 283B or 1420 spectrophotometer, by the $\mathrm{KBr}$ technique. Melting points were obtained on a Melt-Temp II apparatus and are uncorrected. Nuclear magnetic resonance spectra were recorded with a Bruker AV 400 or JEOL Eclipse +300 spectrometer. Chemical shifts for the ${ }^{1} \mathrm{H}$ NMR spectra were recorded in parts per million from tetramethylsilane with the solvent resonance as the internal standard (chloroform, $\delta=7.25 \mathrm{ppm}$ ). Chemical shifts for the ${ }^{13} \mathrm{C}$ NMR spectra were recorded in parts per million from tetramethylsilane using the central peak of $\mathrm{CDCl}_{3}$ $(\delta=77.1 \mathrm{ppm})$ as the internal standard. Mass spectra were recorded with a JEOL JMSAX $505 \mathrm{HA}$ spectrometer at $70 \mathrm{eV}$ using the electronic impact (EI) and fast atom bombardment $\left(\mathrm{FAB}^{+}\right)$technique.

\subsection{Synthesis}

\subsubsection{General Procedure for the Synthesis of 2-Benzylidene-1-Indanones Derivatives}

$o$-Phthalaldehyde was added to a cool sodium hydroxide (1.5 eq.) ethanolic solution with 1 equivalent of acetophenone. The reaction mixture was stirred (around $450 \mathrm{rpm}$ ) at room temperature for approximately 3 hours and then poured into a mixture of ice and commercial hydrochloric acid ( $\mathrm{pH}$ was adjusted to about 7). The resulting solid was filtered and in some cases purified by column chromatography using hexane/ethyl acetate (Figure 1).

\subsubsection{Characterization}

Compound $1\left(\mathrm{C}_{16} \mathrm{H}_{12} \mathrm{O}_{2}, M=236 \mathrm{~g} / \mathrm{mol}\right)$ was prepared starting from $o$-phthalaldehyde $(0.5 \mathrm{~g}, 3.7 \mathrm{mmol})$, acetophenone $(0.48 \mathrm{~g}, 3.7 \mathrm{mmol})$ and $\mathrm{NaOH}(0.119 \mathrm{~g}$, $2.98 \mathrm{mmol})$ and was obtained as a yellow solid, $\mathrm{mp} .90^{\circ} \mathrm{C},(0.67 \mathrm{~g}, 2.82 \mathrm{mmol}$, 75\%). IR: $v 1604,1564 \mathrm{~cm}^{-1} .{ }^{1} \mathrm{H}$ NMR (300 MHz, $\left.\mathrm{CDCl}_{3}\right): \delta=15.067$ (s, $\left.1 \mathrm{H}, \mathrm{OH}\right)$,<smiles>[R]c1ccc(C(C)=O)cc1</smiles>

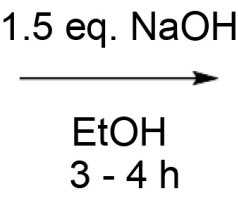

$1 \mathrm{R}=\mathrm{H}$

$2 \mathrm{R}=\mathrm{OMe}$

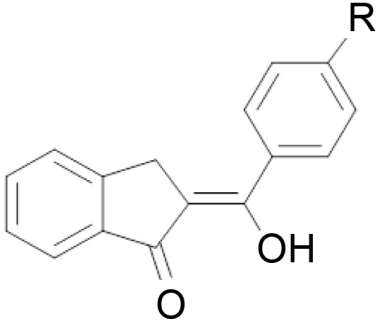

1,2

Figure 1. Synthesis of 2-benzylidene-1-indanone derivative compounds. 
7.49, $7.5(\mathrm{~d}, 1 \mathrm{H}, 1), 7.54(\mathrm{dd}, 1 \mathrm{H}, 2), 7.40(\mathrm{dd}, 1 \mathrm{H}, 3), 7.85(\mathrm{~d}, 1 \mathrm{H}, 4), 7.91(\mathrm{~m}, 1 \mathrm{H}$, 10), 7.48 (m, 3H, 11, 12, 13), 7.91 (m, 1H, 14), 3.86 (sa, 2H, 15) ppm. ${ }^{13} \mathrm{C}$ NMR (75 $\mathrm{MHz}, \mathrm{CDCl}_{3}$ ): $\delta=125.54(\mathrm{C} 1), 133.27$ (C2), 127.40 (C3), 123.36 (C4), 137.85 (C5), 195.70 (C6), 109.41 (C7), 170.79 (C8), 134.79 (C9), 128.07 (C10), 128.55 (C11), 131.21 (C12), 128.55 (C13), 128.07 (C14), 32.19 (C15), 148.51 (C16) ppm. MS (EI): $m / z(\%)=236(1.9 \%)$. HRMS $\left(\mathrm{FAB}^{+}\right)$: calculated for $\mathrm{C}_{16} \mathrm{H}_{12} \mathrm{O}_{2}: 237.0821$. Found: 237.0823 .

Compound $2\left(\mathrm{C}_{17} \mathrm{H}_{14} \mathrm{O}_{3}, M=266 \mathrm{~g} / \mathrm{mol}\right)$ was prepared starting from $o$-phthalaldehyde $(0.5 \mathrm{~g}, 3.7 \mathrm{mmol}), 4^{\prime}$-methoxyacetophenone $(0.56 \mathrm{~g}, 3.7 \mathrm{mmol})$ and $\mathrm{NaOH}(0.119 \mathrm{~g}, 2.98 \mathrm{mmol})$ and was obtained as a yellow solid, mp. $112^{\circ} \mathrm{C}-$ $114^{\circ} \mathrm{C},(0.7 \mathrm{~g}, 2.6 \mathrm{mmol}, 71 \%)$. IR: $v 1601,1566 \mathrm{~cm}^{-1} .{ }^{1} \mathrm{H} \mathrm{NMR}\left(300 \mathrm{MHz}, \mathrm{CDCl}_{3}\right)$ : $\delta=15.33(\mathrm{~s}, 1 \mathrm{H}, \mathrm{OH}), 7.47(\mathrm{~d}, 1 \mathrm{H}, 1), 7.51(\mathrm{dd}, 1 \mathrm{H}, 2), 7.37(\mathrm{dd}, 1 \mathrm{H}, 3), 7.82(\mathrm{~d}$, $1 \mathrm{H}, 4), 7.89$ (d, 2H, 10, 14), 6.95 (d, 2H, 11, 13), 3.82 (s, 2H, 15), 3.83 (s, 3H, 17) ppm. ${ }^{13} \mathrm{C}$ NMR (75 MHz, $\mathrm{CDCl}_{3}$ ): $\delta=125.37$ (C1), 132.85 (C2), 127.23 (C3), 123.03 (C4), 137.87 (C5), 194.84 (C6), 108.32 (C7), 170.04 (C8), 127.00 (C9), 129.99 (C10), 113.88 (C11), 162.06 (C12), 113.88 (C13), 129.99 (C14), 32.45 (C15), 148.09 (C16), 55.30 (C17) ppm. MS (EI): $m / z(\%)=266$ (15\%). HRMS $\left(\mathrm{FAB}^{+}\right)$: calculated for $\mathrm{C}_{17} \mathrm{H}_{14} \mathrm{O}_{3}$ : 267.1021. Found: 267.1023.

\subsubsection{General Procedure for the Synthesis of Oxovanadium Complex of 2-Benzylidene-1-Indanones Derivatives}

A solution of $\mathrm{EtOH}$ with 2-benzylidene-1-indanones derivatives and vanadium (V) oxide $\mathrm{V}_{2} \mathrm{O}_{5}$ was heated under reflux during one night. The resulting greenish blue solid was filtered and crystallized in dichloromethane/hexane solution (Figure 2).

\subsubsection{Characterization}

Compound 1a $\left(\mathrm{C}_{32} \mathrm{H}_{22} \mathrm{O}_{5} \mathrm{~V}, M=537 \mathrm{~g} / \mathrm{mol}\right)$ was prepared starting from $1(0.5 \mathrm{~g}$, $2.1 \mathrm{mmol})$ and $\mathrm{V}_{2} \mathrm{O}_{5}(0.2 \mathrm{~g}, 1.1 \mathrm{mmol})$ in $\mathrm{EtOH}$ and was obtained as a greenish blue solid, mp. $272^{\circ} \mathrm{C}-274^{\circ} \mathrm{C}$. IR: $v 3060,1589,1552$. $\mathrm{MS}\left(\mathrm{FAB}^{+}\right): \mathrm{m} / z(\%)=538$ (10\%). HRMS $\left(\mathrm{FAB}^{+}\right.$): calculated for $\mathrm{C}_{32} \mathrm{H}_{22} \mathrm{O}_{5} \mathrm{~V}\left[\mathrm{M}^{+}\right]$: 537.0907. Found: 534.0915 .
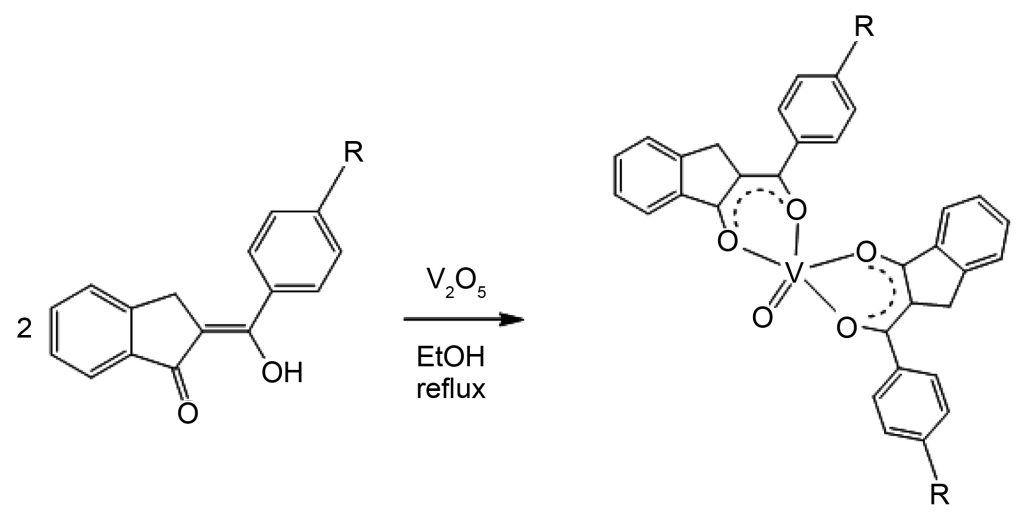

1a $\mathrm{R}=-\mathrm{H}$ 2a $\mathrm{R}=-\mathrm{OMe}$

Figure 2. Synthesis of 2-benzylidene-1-indanone derivative compounds. 
Compound $2 \mathrm{a}\left(\mathrm{C}_{34} \mathrm{H}_{26} \mathrm{O}_{7} \mathrm{~V}, M=597 \mathrm{~g} / \mathrm{mol}\right)$ was prepared starting from $2(0.5 \mathrm{~g}$, $1.9 \mathrm{mmol})$ and $\mathrm{V}_{2} \mathrm{O}_{5}(0.17 \mathrm{~g}, 0.9 \mathrm{mmol})$ in ETOH and was obtained as a green solid, mp. $270^{\circ} \mathrm{C}-272^{\circ} \mathrm{C}$. IR: $v 3056,1595,1544 . \mathrm{MS}\left(\mathrm{FAB}^{+}\right): m / z(\%)=597(100 \%)$. HRMS $\left(\mathrm{FAB}^{+}\right)$: calculated for $\mathrm{C}_{34} \mathrm{H}_{26} \mathrm{O}_{7} \mathrm{~V}\left[\mathrm{M}^{+}\right]$: 537.1112. Found: 534.1118 .

\subsection{Thin Film Deposition and Characterization}

Thin film deposition of the metal complex of 2-benzylidene-1-indanones derivatives was carried out by vacuum thermal evaporation. The material was deposited onto Corning glass and (100) single-crystalline silicon (c-Si) $200 \Omega$-cm wafers. The substrate temperatures were kept at $298 \mathrm{~K}$ during deposition. The evaporation source was a molybdenum boat and the temperature through the molybdenum boat was slowly increased to $498 \mathrm{~K}$. The pressure in the vacuum chamber before the film deposition was $1 \times 10^{-5}$ torr and the evaporation rate was $0.4 \AA / \mathrm{s}$. IR measurements were obtained with a Nicolet iS5-FT spectrophotometer, using silicon flakes as a substrate for the thin films. For SEM, a JEOL field emission electron microscope (JSM7800F) coupled to an Aztec microanalysis system and operated at a voltage of $20 \mathrm{kV}$ and a focal distance of $20 \mathrm{~mm}$, using thin films on a Corning glass substrate, was employed. Ultraviolet-visible spectroscopy was carried out in a Unicam spectrophotometer; model UV300, with a Corning glass. The device consisting of $\mathrm{V}(\mathrm{IV})$ 2-benzylidene-1-indanones derivative particles embedded in nylon 11 matrix was prepared by consecutive evaporation of the polymer and the complex, and then with a heat treatment. The nylon 11 matrix film was prepared onto Corning glass substrates with a contact conductor of indium tin oxide (ITO) by a vapor deposition of a nylon 11 pellet using a double vacuum chamber with a diffusion pump and a special tantalum crucible. The pressure in the vacuum chamber before the film deposition was $\left(1 \times 10^{-6}\right.$ Torr $)$ and the evaporation rate was (70 $\AA / \mathrm{s})$. After the vapor deposition, in order to introduce the vanadium complex particles into the nylon 11 matrix, a heat-treatment at $393 \mathrm{~K}$ for $10 \mathrm{~min}$ was applied. The electric conductivity of the device was studied by means of a fourpoint probe; for these measurements, the substrates are ITO coated glasses with silver strips acting as electrodes. Electric characterization was performed with a programmable voltage source, an auto-ranging pico-ammeter Keithley 4200-SCS$\mathrm{PK} 1$, a sensing station with lighting controller circuit and a sensing station with temperature controller circuit Next Robotix.

\section{Results and Discussion}

As far we know, there is not a net influence of the different moiety groups in these ligands. We used our methodology to synthesized 2-benzylidene-1-indanone derivatives to obtain compounds $1 \mathrm{a}$ and $2 \mathrm{a}$ [12]. IR analysis is shown in Table 1. Here, the absence of absorption in the $1600 \mathrm{~cm}^{-1}$ region was considered evidence that the coordination occurs through the enol tautomer. The signal at $1590 \mathrm{~cm}^{-1}$ was attributed to the carbonyl bond $(\mathrm{C}=\mathrm{O})$, that is moved to lower frequencies. In addition, we observed a characteristic $\mathrm{V}=\mathrm{O}$ band around $980 \mathrm{~cm}^{-1}$, while the 1300 and $1380 \mathrm{~cm}^{-1}$ signals were assigned to the C-O-V vibrational band [13] [14] 
Table 1. IR $\left(\mathrm{cm}^{-1}\right)$ characteristic bands for powder and thin films.

\begin{tabular}{ccccc}
\hline \multirow{2}{*}{ Compound } & \multicolumn{4}{c}{ IR characteristic bands } \\
\cline { 2 - 5 } & $v(\mathrm{C}=\mathrm{O})$ & $v(\mathrm{C}-\mathrm{O})$ & $v(\mathrm{~V}=\mathrm{O})$ & $v(\mathrm{C}-\mathrm{O}-\mathrm{V})$ \\
\hline 1a (pellet) & 1588 & 1551 & 970 & 1327 \\
1a (thin film) & 1589 & 1554 & 998 & 1328 \\
2a (pellet) & 1594 & 1545 & 986 & 1327 \\
2a (thin film) & 1600 & 1550 & 992 & 1328 \\
\hline
\end{tabular}

[15]. The $\mathrm{V}=\mathrm{O}$ bond may be considered as multiple bonds, where the $\pi$ bond, is produced by an $\mathrm{O}-\mathrm{V}$ electronic donation of the $p \pi-d \pi$ type. The donation degree depends on the capacity of the oxygen atom to give electrons and the vanadium atom to accept them. Oxygen gives electrons due to its high electronic density by having full the valence shell and its low volume. On the other hand, after thin film deposition, a comparison of the IR absorption spectra of the synthesized complexes and those of the deposited films on silicon substrates (Table 1) indicated that thermal evaporation is a good technique to obtain oxovanadium complexes of 2-benzylidene-1-indanone derivatives films because it showed no decomposition of the complexes. The IR spectroscopy results on the films gave a clear clue of their thermal stability. This is a relevant aspect, considering that, if these materials have semiconductor behavior, the electric transport is expected to increase with temperature, without any modification in the structural and chemical composition. 2-benzylidene-1-indanone metal complexes derivatives with oxovanadium can form compounds with strong metal-ligand covalent bonds, which enhance the molecular stability and support the sublimation process without dissociation [16]. There are few differences between powder materials and their deposition on films, and they may be due to internal stress produced during the vaporization process.

In order to promote a semiconductor behavior with the vanadium complexes, it was necessary to guarantee the chemical stability of the molecule at high temperatures, since the electronic delocalization and the mobility of the charge carriers between the coordination sphere of the vanadium atom and the ligand, is crucial. In order to complement the IR Spectroscopy results and to verify the metallic complexes stability after evaporation, an additional EDS analysis was performed. Figure 3 shows results for thin films of vanadium compound 1a, where the presence of silicon is due to the substrate layer where they were deposited. The presence of the metal and the coordinated oxygen, are observed. Similar results were obtained for the $2 \mathrm{a}$ thin film. In semiconductor materials, it is fundamental that increases in temperature, the electric conductivity in thin films, be increased as well. The stability presented by the vanadium complexes will be decisive for the electric charges transport along the molecule as the temperature is increased, as long as the thin film of the complex shows a uniform morphology, which avoids the dissipation of electric charges.

To know the homogeneity and morphology of the films, SEM images from samples deposited on monocrystalline silicon were obtained. The SEM micro- 


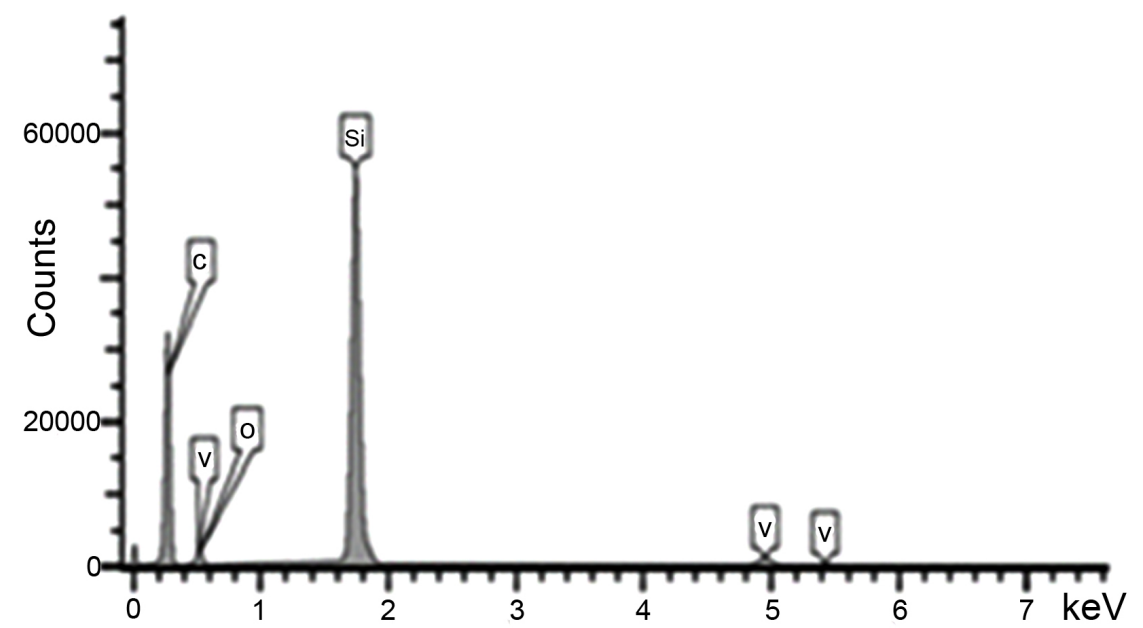

Figure 3. EDS for complex of vanadium thin film.

graphs in Figure 4 show the surface morphologies of 2-benzylidene-1-indanone derivative films. The vanadium compound films (Figure 4(a) \& Figure 4(b)), showed a fine and homogeneous appearance with a flat surface with small defects. The presence of more small holes in the 2a film with the methoxy radical can be also explained in terms of the intermolecular forces and the polarity of radical. This polarity generates a high cohesion force within the molecule, and a low adherence force between the molecule and the substratum, giving as a result, the formation of a great number of pores. So in order for these compounds to be used in optoelectronic applications, it is necessary to avoid the formation of pores, which in this study, will be made by the introduction of the vanadium complex, in a nylon 11 polymeric matrix. Additionally, the compound with the methoxy group in Complex 2a, is the one that presents a higher size of particle (Figure 4(b) \& Figure 4(d)); apparently, during the deposit of this compound, it was generated a lower number of nuclei than in the growing stage, and developed in higher size that in the case of Compound 1a, which probably had a high nucleation with low growth rate. From the foregoing, Compound 2a also presents higher heterogeneity and higher roughness. This is a relevant aspect since a low roughness homogeneous surface will provide a more efficient electronic transport, and therefore, good semiconductor behavior. Thickness is another important aspect to consider; the film from Compound 2a shows much higher thickness at the same deposition conditions and speed that the film from Compound 1a. From all the above, we would expect that the Compound 1a film would be more suitable to present semiconducting behavior and a higher electron flow along the complex molecules. An initial test to evaluate the conductive behavior of these films was through the measurement of the optical activation energy or optical band GAP. This value, which gives a measure of the energy needed for an electron to jump from the HOMO to the LUMO, will be initially obtained by using UV-vis spectroscopy and then the absorption coefficient $(\alpha)$, the photon energy $(h v)$, and finally, the band GAP value.

The UV-vis spectra of vanadium film complexes of 2-benzylidene-1-indano- 


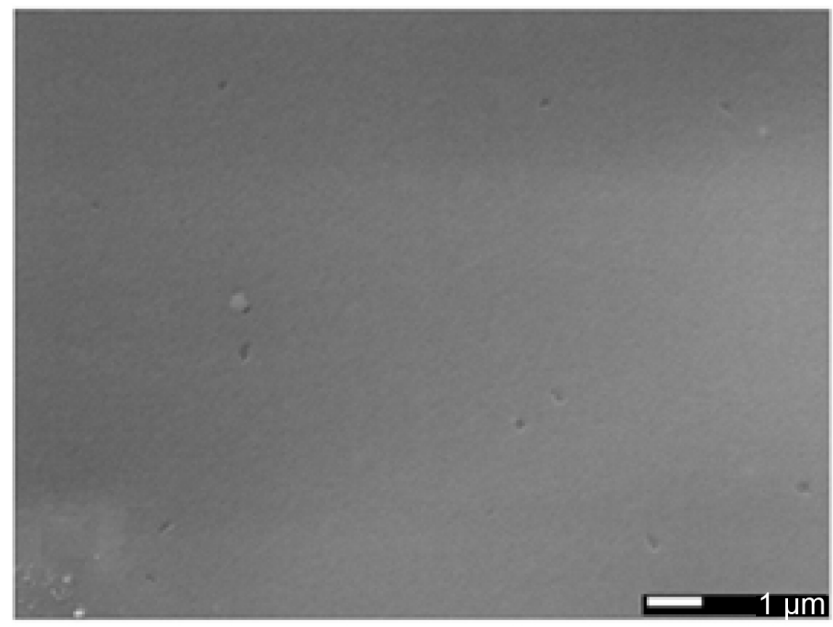

(a)

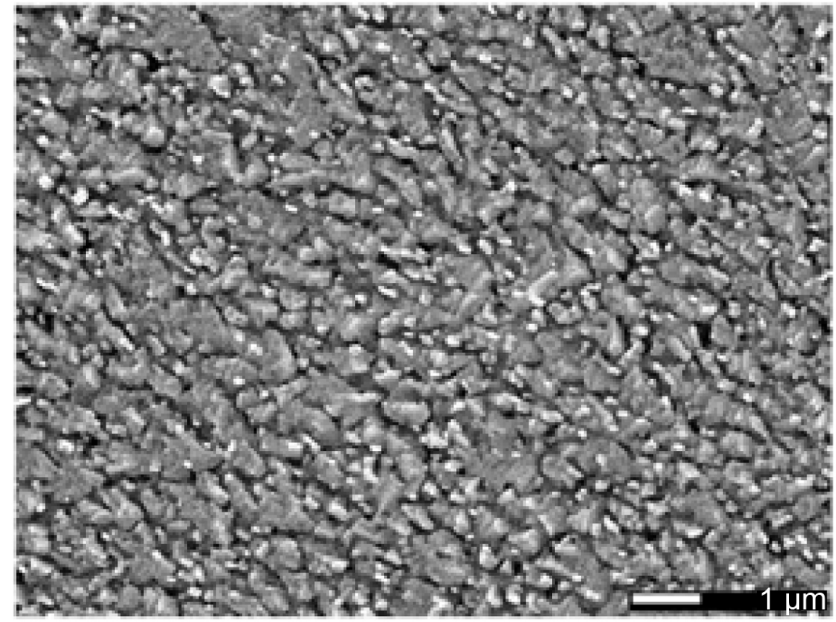

(c)

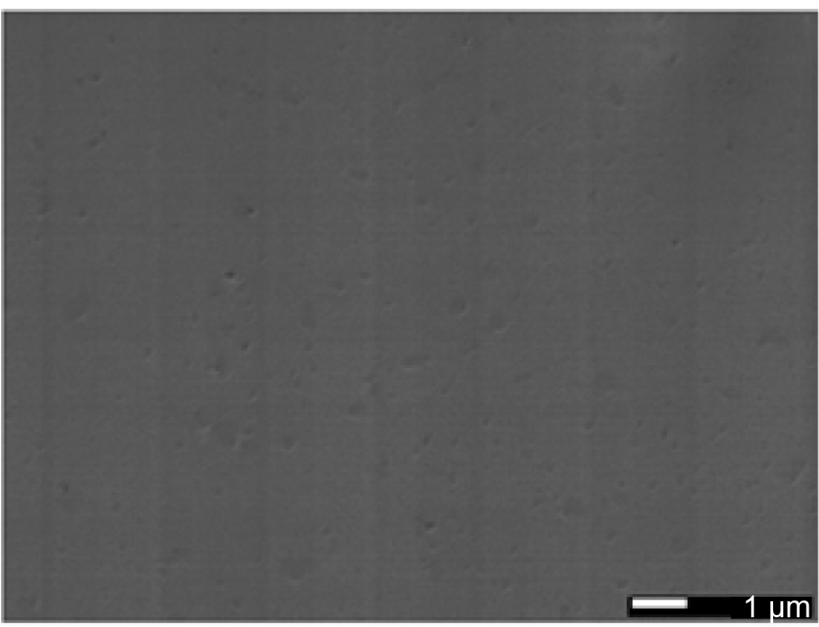

(b)

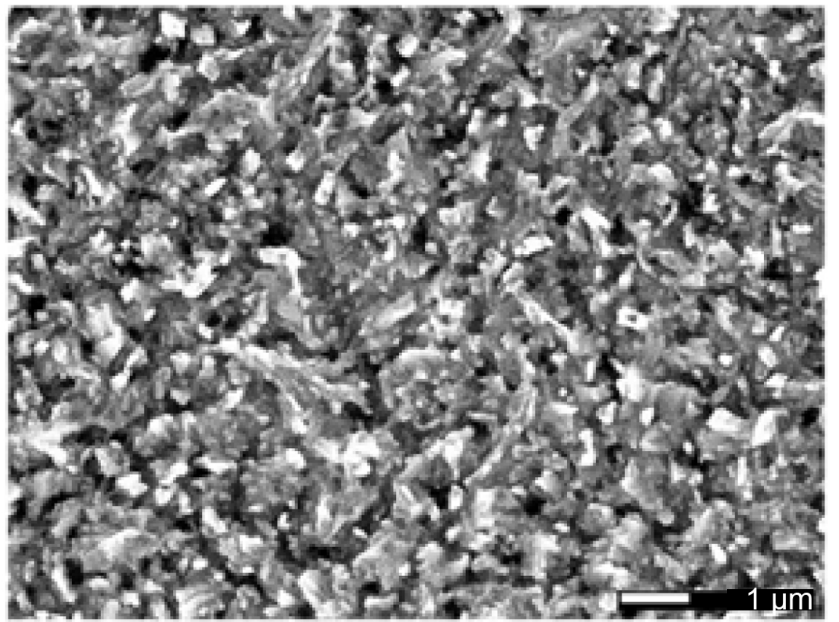

(d)

Figure 4. SEM micrographs of materials (a) 1a, (b) 2a at $8000 \times$ and (c) 1a, (d) 2a at 20,000x.

ne derivatives were acquired in Corning glass substrates at room temperature. The electronic spectral data of the thin films is given in Table 2. For oxovanadium complexes, 1a and 2a UV-vis spectra exhibited bands around $226 \mathrm{~nm}$ and $271 \mathrm{~nm}$ due to $\pi \rightarrow \pi^{*}$ intra-ligand transitions of the aromatic rings. The latter band is blue shifted around $376 \mathrm{~nm}$ on complexation. In addition, low intensity bands at $386 \mathrm{~nm}$ for oxovanadium complexes are assigned to charge transfer transition (MLCT). A weak shoulder at $391-406 \mathrm{~nm}$ in is attributed to $d-d$ transition [5]. The $\alpha$ of vanadium complexes of 2-benzylidene-1-indanone derivative thin films was calculated at different energies. The dependence of $(\alpha h v)^{1 / r}$ on $h v$ was evaluated and plotted for $r=2$ in Figure 5. This characteristic behavior corresponds to electronic indirect transitions between the valence band and the conduction band [15] [17]. The indirect electronic transitions seem to be of the $\pi$ to $\pi^{*}$ type and the optical GAP could be determined by the extrapolation to zero of the linear regions of the $(\alpha h v)^{1 / 2}=f(h v)$ plots [17] [18] [19]. The band GAP energies calculated are presented in Table 2 and were found in the range between 2.6 
Table 2. Characteristic parameters of the thin films.

\begin{tabular}{cccc}
\hline Thin Film & UV-Vis Data $\lambda(\mathrm{nm})$ & $\begin{array}{c}\text { Film Thickness } \\
(\AA)\end{array}$ & Indirect Optical \\
\hline 1a & $272,379,406$ & 40 & 2.7 \\
2a & $226,271,376,386,391$ & 1527 & 2.6 \\
\hline
\end{tabular}

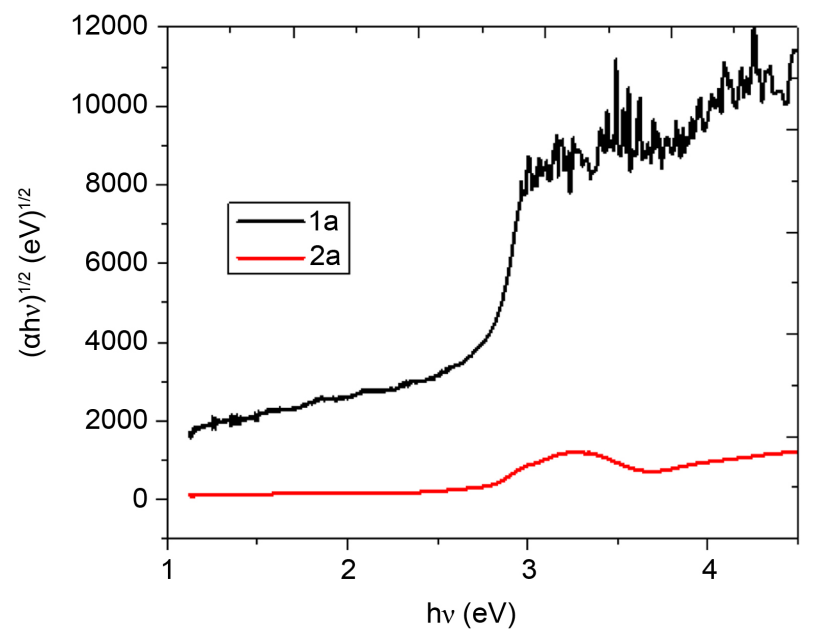

Figure 5. Plot of $(\alpha / h v)^{1 / 2}$ vs. photon energy $h v$ of vanadium complexes of 2-benzylidene-1-indanone derivative thin films.

and $2.7 \mathrm{eV}$. This variation is minimal and is mainly due to the change of radical and its polarity in the vanadium complexes $1 \mathrm{a}$ and $2 \mathrm{a}$.

By comparing the behavior to vanadium complexes in Figure 5, a minimal variation of the parameter related to the absorption coefficient for indirect transitions $(\alpha h v)^{1 / 2}$ is observed. Based on these results, as well as the GAP values obtained for vanadium complexes, the latter ones are considered organic semiconductors and may be used in the manufacture of optoelectronic devices. Apparently, in the $\mathrm{V}(\mathrm{IV})$ thin films, the $[\mathrm{Ar}] 3 \mathrm{~d}^{1}$ configuration can favor the electronic transitions between HOMO and LUMO orbitals with organic semiconductor. From these results, V(IV) complexes of 2-benzylidene-1-indanone derivatives may prove to be suitable candidates for photovoltaic applications. In addition, their semiconductor-like properties may also allow their use in sensors and molecular electronics applications [14] [19]. Is important to note that when comparing the plots in Figure 5 for vanadium films 1a and 2a, the first one presents a greater ease of electronic transport than the second one, probably due of the better thin film quality as shown in Figure 4. The considerable amount of holes and the superior size of particles in compound 2a make it difficult for this compound to be used for optoelectronic applications, although apparently, its activation energy value is slightly low. Because of this, film 1a is more appropriated for the manufacture of a device where the electric properties are evaluated. The small size in its structure, allows also suitable introduced into the polymer matrix of nylon 11, and by this, a suitable flow of electric charges along the film of the device.

As mentioned above, in order to evaluate the electrical properties of the thin 
films for their use in optoelectronics, a multilayer glass/ITO/nylon 11/1a complex/Ag device was fabricated by using the thermal relaxation technique. One crucial factor that affects the operation of these devices is the protection of the organic semiconductor against harsh environmental conditions [20]. For the further reduction of the permeation of $\mathrm{O}_{2}$ and $\mathrm{H}_{2} \mathrm{O}$ molecules, we propose the subsequent deposition of $\mathrm{V}(\mathrm{IV})$ complex of 2-benzylidene-1-indanone derivative onto a polymeric matrix. The permeation was mainly controlled by the nylon 11 matrix, the barrier nano-layers induced by the intrinsic roughness, the surface and the structure inhomogeneities [20]. The nylon 11/1a bilayer complex was kept for $10 \mathrm{~min}$ at $393 \mathrm{~K}$, for the purpose of conducting a thermal relaxation in the polymer matrix and the subsequent introduction of particles to vanadium complex. The $I-V$ behavior was obtained to evaluate the electric current properties of this hybrid device. Figure 6(a) shows the behavior of the vanadium device under illumination when the current due to hole injection from the positively biased ITO. Regardless of the wavelength of the incident radiation, the device follows the same overall behavior. This result is important since the manufacture of devices for optoelectronic and photovoltaic applications are sensitive to the kind of incident radiation or wavelength and therefore can be critical for the semiconductor behavior. Apparently, in this material at a fixed voltage, the absence of radiation and the white light, promote higher electric transport, while the ultraviolet radiation produces lower electric charge transported along the device. Additionally, and according to Figure 6(a), at lower voltages below $7 \mathrm{~V}$, an ohmic conduction is evident. However, at this voltage, it is observed a slight change in the slope of the curves, which may be a result of space-charge limited conductivity (SCLC), governed by an exponential trap distribution. This can be explained by a small energy barrier at the ITO/nylon 11/1a complex interfaces, given rise to SCLC bulk current when ITO is positively biased [21].

The conducting behavior of vanadium complex was evaluated by increasing the temperature, with the purpose to complement the information regarding its semiconducting behavior and its usage for optoelectronic devices. In one hand, Figure $6(\mathrm{~b})$ shows the temperature dependence of electric conductivity for a constant applied voltage $(5,10,15$ and $20 \mathrm{~V})$. The variations observed in the electric conductivity are practically negligible, as the electrical transport in the device increases with temperature. The increase starts as soon as charge carriers acquire large enough activation energies. From these plots, the electrical conductivity was evaluated at $25^{\circ} \mathrm{C}$ and the results are between $3.7 \times 10^{-3} \Omega^{-1} \cdot \mathrm{cm}^{-1}$ and $4.5 \times 10^{-3} \Omega^{-1} \cdot \mathrm{cm}^{-1}$. Electrical conductivity values for all voltages are in the range of semiconductor materials $\left(10^{-6}-10^{1} \Omega^{-1} \cdot \mathrm{cm}^{-1}\right)$ [22]. On the other hand, the analysis of Figure 6(b) shows that the curves for the vanadium device have three sections with different slopes. The existence of trap levels in the energy GAP is confirmed by the presence of more than one linear portion as seen in the figure. Electrons or holes can travel from one kind of molecule to another. Therefore, $\pi$-electrons can also hop from V(IV) complexes of 2-benzylidene-1-indanone molecule to another if orbitals with the same energy levels exist between them. 


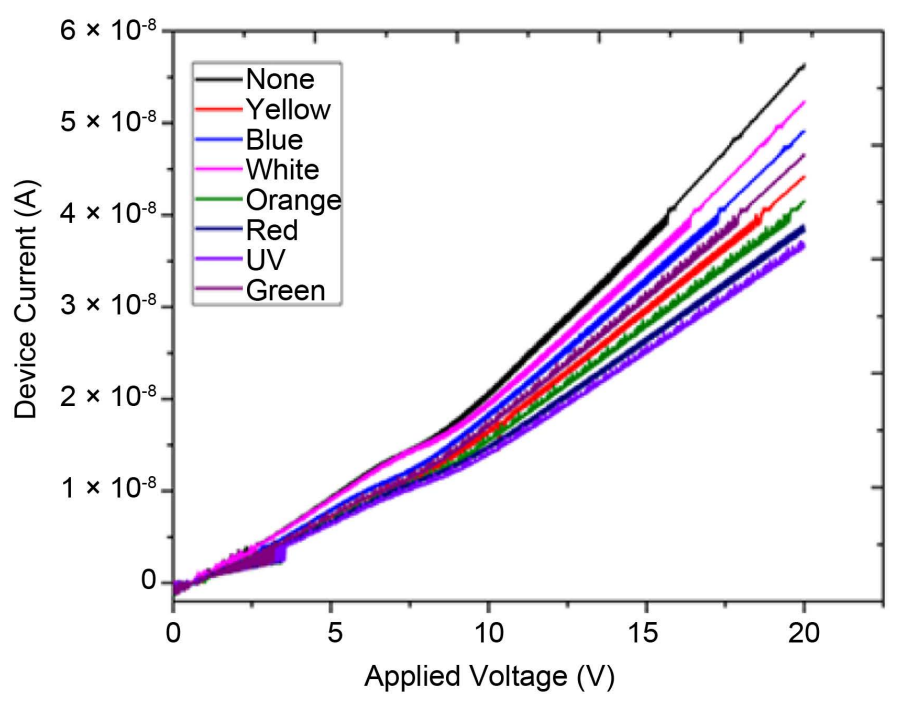

(a)

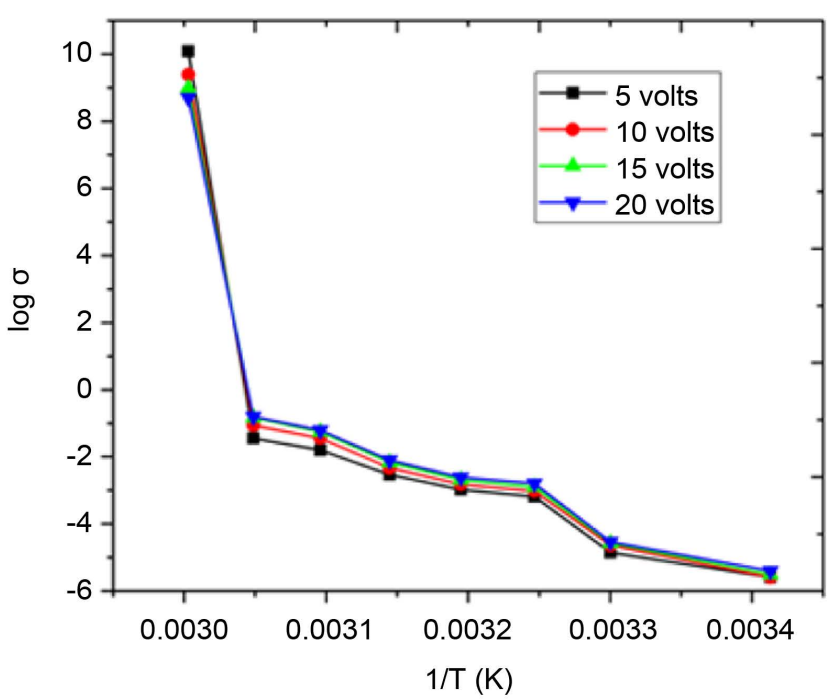

(b)

Figure 6. (a) Current-voltage characteristics and (b) Electrical conductivity as a function of temperature of the glass/ITO/nylon 11/1a complex/Ag device (in air) under illumination.

Additionally, electrons can hop from the metallic atom to the 2-benzylidene-1indanone ligand. A plot of $\ln \sigma$ versus $1 /$ T yields a straight line which slope can be used to determine the thermal activation energies $\left(\mathrm{E}_{\mathrm{a}}\right)$ of the vanadium films [23]. The calculated $\mathrm{E}_{\mathrm{a}}$ are between $2.17 \mathrm{eV}$ for $20 \mathrm{~V}$ to $2.31 \mathrm{eV}$ for $5 \mathrm{~V}$. These values are slightly lower than the ones obtained in the optical band GAP by the absorption coefficient and the photon energy. However, in addition to the electrical behavior due to increases in temperature and changes in the wavelength of the incident radiation, these values could suggest that this arrangement can be used in optoelectronics applications. Apparently, the presence of nylon 11 protects the vanadium complex from possible degradation and allows the pass of electric current through the semiconducting compound. 


\section{Conclusion}

New vanadium complexes were synthesized with moderated yields with an easy and clean reaction and were also characterized. Due to their physical properties, vanadium indanone thin films were deposited by thermal vacuum evaporation. Thin film morphology seems to depend on the molecular structure of the ligand around de vanadium atom; polarity in the radical of ligand is a decisive factor for the morphology and thickness of the formed film. The optical band gap was calculated and the values were found to be around $2.7 \mathrm{eV}$ for indirect transitions. Differences in the GAP values were possibly related to factors such as the radical in the molecule, differences in size of the particles in the film and the molecular overlap of the thin film. 2-benzylidene-1-indanone vanadiummultilayer structure involving conductor-semiconductor interfaces has been fabricated using ITO and silver contact materials among others. The incidence radiation with different wavelengths on the device produced an ohmic behavior at values lower than $7 \mathrm{~V}$, while an SCLC mechanism at values higher than $7 \mathrm{~V}$ was evidence. The effect of temperature on the conductivity was also evaluated and showed typical semiconducting characteristics. The existence of trap levels is confirmed by the presence of three linear portions in the $\ln \sigma$ vs. $1 / \mathrm{T}$ plots. From this work, ITO/nylon 11/vanadiumindanone/Agarrangements show potentially useful electronic properties that may be employed in the production of electronic devices for optoelectronic applications.

\section{Acknowledgements}

The authors wish to thank the technical assistance of Rocío Patiño, Luis Velasco, Javier Pérez, Isabel Uribe, and also C. González Normandía. The authors gratefully acknowledge the financial support of CONACYT Project 127796 and DGAPAPAPIIT Project IN207414. We would also like to thank CONACYT for the Ph.D. grant extended to M. L. G.

\section{References}

[1] Tress, W. (2014) Organic Solar Cells. Theory, Experiment, and Device Simulation. Chapter 3, Springer International Publishing, Switzerland, 67-214.

[2] Abe, Y., Iyoda, A., Seto, K., Moriguchi, A. and Yokoyama, H. (2008) Synthesis, Strucutres and Ion-Association Properties of a Series of Schiff Base Oxidovanadium (V) Complexes with 4-Substituted Long Alkoxy Chains. European Journal of Inorganic Chemistry, 13, 2148-2157. https://doi.org/10.1002/ejic.200701116

[3] Tantrawong, S., Styring, P. and Goodby, J.W. (1993) Discotic Mesomorphism in Oxovanadium (IV) Complexes Possessing Four Alkyl Substituents. Journal of Materials Chemistry, 3, 1209-1216. https://doi.org/10.1039/jm9930301209

[4] Hazra, M., Dolai, T., Pandey, A., Dey, S.K. and Patra, A. (2014) Synthesis and Characterisation of Copper(II) Complexes with Tridentate NNO Functionalized Ligand: Density Function Theory Study, DNA Binding Mechanism, Optical Properties, and Biological Application. Bioinorganic Chemistry and Applications, 2014, Article ID: 104046.

[5] Bhattacharjee, C.R., Das, G., Dhar, D., Kanoo, P. and Mondal, P. (2011) Vanadyl 
(IV) Complexes of 4-Alkoxy Substituted [N, O] Donor Salicylaldimine Schiff Bases Deried from Chloro-/Nitro-Aniline: Synthesis, Mesomorphism, and DFT Study. Journal of Coordination Chemistry, 64, 2746-2760. https://doi.org/10.1080/00958972.2011.606461

[6] Zhao, X.J., Xue, L.W. and Zhao, G.Q. (2013) Synthesis, Structures, and Antimicrobial Activities of Dimeric Oxovanadium V Complexes with Tridentate Shiff Bases. Synthesis and Reactivity in Inorganic, Metal-Organic, and Nano-Metal Chemistry, 43, 1344-1348. https://doi.org/10.1080/15533174.2012.751420

[7] Bocknack, B.M., Wang, L.C., Hughes, F.W. and Krische, M.J. (2005) Chiral b-Diketonate Ligands of "Pseudo Planar Chiral" Topology: Enantioselective Synthesis and Transition Metal Complexation. Tetrahedron, 61, 6266-6275. https://doi.org/10.1016/j.tet.2005.03.118

[8] Barberá, J., Iglesias, R., Serrano, J.L., Sierra, T., De la Fuente, M.R., Palacios, B., Pérez-Jubindo, M.A. and Vázquez, J.T. (1998) Switchable Columnar Metallomesogens. New Helical Sel-Assemblig Systems. Journal of American Chemical Society, 120, 2908-2918. https://doi.org/10.1021/ja9735012

[9] Stilinović, V., Bučar, D.K., Halasz, I. and Mestrovic, E. (2013) V=O...C Interactions Inf Crystal Structures of Oxovanadium-Coordination Compounds. New Journal of Chemistry, 37, 619-623. https://doi.org/10.1039/C2NJ40780A

[10] Lee, H. and Song, B.J. (2012) P-Type Copper Oxide Thin Films Deposited by Vacuum Evaporation. Molecular Crystals and Liquid Crystals, 564, 198-205.

https://doi.org/10.1080/15421406.2012.696509

[11] Perez, M.D., Borek, C., Djurovich, P.I., Mayo, E.I., Lunt, R.R., Forrest, S.R. and Thompson, M.E. (2009) Organic Photovoltaics Using Tetraphenylbenzoporphyrin Complexes as Donor Layers. Advanced Materials, 21, 1517-1520. https://doi.org/10.1002/adma.200802683

[12] Lozano González, M., Sánchez-Vergara, M.E., Álvarez, J.R., Chávez-Uribe, M.I., Toscano, R.A. and Álvarez-Toledano, C. (2014) Synthesis and Optical Properties of Iron (III) Complexes of 2-Benzylidene-1-Indanone Derivative Thin Films. Journal of Materials Chemistry C, 2, 5607-5614. https://doi.org/10.1039/c4tc00599f

[13] Zabicky, J. (2009) Patai Series: The Chemistry of Functional Groups. In: Rappoport, Z., Ed., The Chemistry of Metal Enolates, Part 1, Vol. 2, John Wiley \& Sons Ltd., Hoboken, 84-108.

[14] Hancock, R.D. and Thornton, D.A. (1970) Interactions in Metal B-Ketoenolates. Theoretica Chimica Acta, 18, 67-74.

[15] Selbin, J., Holmes, L.H. and McGlynn, S.P. (1963) Electronic Structure, Spectra and Magnetic Properties of Oxycations-IV Ligation Effects on the Infra-Red Spectrum of the Vanadyl Ion. Journal of Inorganic and Nuclear Chemistry, 25, 1359-1369. https://doi.org/10.1016/0022-1902(63)80404-2

[16] Giricheva, N.I., Girichev, G.V., Kuzmina, N.P., Medvedeva, Y.S. and Rogachev, A.Y. (2009) Structure of the $\mathrm{Cu}$ (Salen) Molecule $\mathrm{CuO}_{2} \mathrm{~N}_{2} \mathrm{C}_{16} \mathrm{H}_{14}$ According to Gas-Phase Electron Diffraction Data and Quantum Chemical Calculations. Journal of Structural Chemistry, 50, 52-59. https://doi.org/10.1007/s10947-009-0007-1

[17] Cody, G.D. (1984) Hydrogenated Amorphous Silicon, Part B, Optical Properties. In: Pankove, J.I., Ed., Semiconductors and Semimetals, Vol. 21, Academic Press Inc., Orlando.

[18] Leontie, L., Roman, M., Brinza, F., Podaru, C. and Rusu, G.I. (2003) Electrical and Optical Properties of Some New Synthesized Ylides in Thin Films. Synthetic Metals, 138, 157-163. https://doi.org/10.1016/S0379-6779(02)01277-8

[19] Adachi, S. (1999) Optical Properties of Crystalline and Amorphous Semiconduc- 
tors: Materials and Fundamental Principles. Kluwer Academic Publishers, Boston. https://doi.org/10.1007/978-1-4615-5241-3

[20] Logothetidis, S. (2008) Flexible Organic Electronic Devices: Materials, Process and Applications. Materials Science and Engineering B, 152, 96-104.

https://doi.org/10.1016/j.mseb.2008.06.009

[21] Mahapatro, A.K. and Ghosh, S. (2007) Charge Carrier Transport in Metal Phthalocyanine Based Disordered Thin Films. Journal of Applied Physics, 101, Article ID: 034318. https://doi.org/10.1063/1.2434946

[22] Sánchez Vergara, M.E., Islas Bernal, I.F., Rivera, M., Ortiz Rebollo, A. and Alvarez Bada, J.R. (2007) Formation and Characterization of Thin Films from Phthalocyanine Complexes: An Electrosynthesis Study Using the Atomic-Force Microscope. Thin Solid Films, 515, 5374-5380. https://doi.org/10.1016/j.tsf.2007.01.033

[23] Sarkar, S., Aydogdu, Y., Dagdelen, F., Bhaumik, B.B. and Dey, K. (2004) X-Ray Diffraction Studies, Thermal, Electrical and Optical Properties of Oxovanadium (IV) Complexes with Quadridentate Schiff Bases. Materials Chemistry and Physics, 88, 357-363. https://doi.org/10.1016/j.matchemphys.2004.08.001

Submit or recommend next manuscript to SCIRP and we will provide best service for you:

Accepting pre-submission inquiries through Email, Facebook, LinkedIn, Twitter, etc. A wide selection of journals (inclusive of 9 subjects, more than 200 journals)

Providing 24-hour high-quality service

User-friendly online submission system

Fair and swift peer-review system

Efficient typesetting and proofreading procedure

Display of the result of downloads and visits, as well as the number of cited articles

Maximum dissemination of your research work

Submit your manuscript at: http://papersubmission.scirp.org/

Or contact ampc@scirp.org 